\title{
AMPK is required for uterine receptivity and normal responses to steroid hormones
}

\author{
Richard M Griffiths IV1, Cindy A Pruํ, Susanta K Behura², Andrea R Cronrath¹, \\ Melissa L McCallum ${ }^{1}$, Nicole C Kelp, Wipawee Winuthayanon ${ }^{1}$, Thomas E Spencer ${ }^{2}$ and \\ James K Pru ${ }^{1}$ \\ ${ }^{1}$ Department of Animal Sciences, School of Molecular Biosciences, and Center for Reproductive Biology, \\ Washington State University, Pullman, Washington, USA and ${ }^{2}$ Division of Animal Sciences and Department of \\ Obstetrics, Gynecology, and Women's Health, University of Missouri, Columbia, Missouri, USA
}

Correspondence should be addressed to J K Pru; Email: jpru@wsu.edu

\begin{abstract}
We previously demonstrated that 5'-AMP-activated protein kinase (AMPK) is essential for normal reproductive functions in female mice. Conditional ablation of Prkaa1 and Prkaa2, genes that encode the $\alpha 1$ and $\alpha 2$ catalytic domains of AMPK, resulted in early reproductive senescence, faulty artificial decidualization, uterine inflammation and fibrotic postparturient endometrial regeneration. We also noted a delay in the timing of embryo implantation in Prkaa1/2 ${ }^{d / d}$ female mice, suggesting a role for AMPK in establishing uterine receptivity. As outlined in new studies here, conditional uterine ablation of Prkaa1/2 led to an increase in ESR1 in the uteri of Prkaa1/2 $2^{d / d}$ mice, resulting in prolonged epithelial cell proliferation and retention of $E_{2}$-induced gene expression (e.g. Msx1, Muc1, $L t f)$ through the implantation window. Within the stromal compartment, stromal cell proliferation was reduced by five-fold in Prkaa1/2 $2^{d / d}$ mice, and this was accompanied by a significant decrease in cell cycle regulatory genes and aberrant expression of decidualization marker genes such as Hand2, Bmp2, Fst and Inhbb. This phenotype is consistent with our prior study, demonstrating a failure of the Prkaa1/2 ${ }^{d / d}$ uterus to undergo decidualization. Despite these uterine defects, ovarian function seemed to be normal following ablation of Prkaa1/2 from peri-ovulatory follicles in which ovulation, luteinization and serum progesterone levels were not different on day 5 of pregnancy or pseudopregnancy between Prkaa1/2 ${ }^{f / f l}$ and Prkaa1/2 ${ }^{d / d}$ mice. These cumulative findings demonstrate that AMPK activity plays a prominent role in mediating several steroid hormone-dependent events such as epithelial cell proliferation, uterine receptivity and decidualization as pregnancy is established.

Reproduction (2020) 159 707-717
\end{abstract}

\section{Introduction}

Uterine receptivity is established by the sequential actions of estrogen $\left(\mathrm{E}_{2}\right)$ and progesterone $\left(\mathrm{P}_{4}\right)$ that act through their nuclear receptors to change the expression of critical genes. Several of these genes have been shown through conditional mutagenesis in mice to be fundamentally required for the establishment of early pregnancy, some of which include leukemia inhibitory factor (Lif), follistatin $(F s t)$, bone morphogenetic protein 2 (Bmp2), heart- and neural crest derivatives-expressed protein 2 (Hand2), Msh homeobox 1 (Msx1) and Indian hedgehog (Ihh) (Stewart et al. 1992, Simon et al. 2009, Daikoku et al. 2011, Li et al. 2011, 2013, Bhurke et al. 2016, Cheng et al. 2017, Fullerton et al. 2017). The proliferative and differentiative actions of sex steroid hormones are not direct. Rather, the hormones up-regulate expression of paracrine factors that, in turn, coordinate proliferative events induced by $E_{2}$ and differentiation events directed by $\mathrm{P}_{4}$. While many of the paracrine ligands and their cognate receptors that mediate female sex steroid hormone actions in the uterus have been characterized, much less is known about the signal transduction pathways linked to these receptors. It is known that the MAPK, AKT and STAT3 signaling pathways play prominent roles in uterine receptivity and decidualization (Cheng et al. 2001, Yoshino et al. 2003, Singh et al. 2011, Yin et al. 2012, Salleh \& Giribabu 2014, Makker et al. 2018, Yoo et al. 2018).

AMP-activated protein kinase (AMPK) is an essential component of the signal transduction pathway that serves as a cellular sensor of energy status (Viollet et al. 2009). AMPK is a highly conserved heterotrimeric protein complex consisting of a catalytic $\alpha$ subunit and regulatory $\beta$ and $\gamma$ subunits. The Prkaa 1 and Prkaa2 genes encode the $\alpha 1$ and $\alpha 2$ AMPK catalytic domains, respectively. In response to elevated cellular AMP, AMPK initiates catabolic processes while simultaneously inactivating energy depleting anabolic pathways (Hardie et al. 2006, Horman et al. 2012, Hardie \& Lin 2017). AMPK 
plays a vital role in placental development (Kaufman \& Brown 2016). Stable shRNA knockdown of Prkaa1 and Prkaa2 (Prkaa1/2) in trophoblast labyrinth cells results in changed morphology, growth rate and nutrient transport (Carey et al. 2014). More specifically, Prkaa $1 / 2$ knockdown reduce trophoblast glycolysis, mitochondrial respiration and ATP coupling efficiency (Waker et al. 2017). In contrast, excessive AMPK activity alters fatty acid metabolism and impairs trophoblast invasiveness in preeclampsia (Yang et al. 2018). These collective findings indicate that AMPK activity must be tightly regulated for normal placental development. AMPK may also play an anti-inflammatory role in fetal membranes, as its expression decreases at term. Furthermore, pharmacological activation of AMPK with phenformin or 5-Aminoimidazole-4-carboxamide ribonucleotide (AICAR) reduced infection-induced expression of proinflammatory cytokines in extraembryonic membranes of pregnancies with preterm premature rupture of the membranes (PPROM) (Lim et al. 2015). It is interesting to note that obese women have reduced placental expression and activity of AMPK, which correlates with poor placental and pregnancy outcomes (Martino et al. 2016). Reduced placental expression of the active form of AMPK inversely correlates with birth weight (Jansson et al. 2013). Reduced placental AMPK expression/activity also generates a lipotoxic placental environment and an associated decrease in angiogenesis and increased expression of markers of inflammation and oxidative stress (Saben et al. 2014). The correlation between obesity and reduced placental AMPK expression/activity is also present in other animals. AMPK activity is reduced in cotyledonary tissue in obesogenic ewes (Zhu et al. 2009). Administration of AICAR reduced hypertension and angiogenic imbalance in a rat model of preeclampsia where increased AMPK activity reestablished placental antioxidant activities (Banek et al. 2013).

The known functions of AMPK in the female reproductive system are limited. Based on pharmacological studies, AMPK activation decreases steroidogenesis in rat and bovine granulosa cells (Tosca et al. 2005, 2006, 2007a, 2010). A role for AMPK in oocyte maturation is species-dependent where AMPK catalytic activity results in oocyte activation in mice, but inhibition in pigs and cattle (Mayes et al. 2007, Tosca et al. 2007b, Santiquet et al. 2014, Bertoldo et al. 2015). Within the uterus, P53 was suggested to modulate uterine AMPK activity, which in turn controlled the timing of parturition in a murine model of preterm birth (Deng et al. 2016). Polymorphisms in the PRKAA1 gene are thought to enhance adaptation to high altitudes during pregnancy in Andean women by influencing uterine artery diameter, fetal growth and birth weight outcomes (Bigham et al. 2014). Steroid hormones were shown to regulate expression of facilitative glucose transporters in murine uterine epithelial tissue in an AMPK-dependent fashion (Kim \& Moley 2009). Beyond these limited findings, relatively little is known about the role of AMPK in female reproduction, particularly on the uterine side of the maternal:fetal interface during pregnancy. We recently established that conditional mutagenesis of Prkaa1 and Prkaa2 in the uterus results in subfertility that rapidly progresses to complete infertility and significantly reduced fecundity (McCallum et al. 2018). Additional phenotypes included uterine inflammation and abnormal postparturient deposition of fibrotic tissue in the endometrium, indicative of endometritis. Here, we evaluated AMPK as a mediator of steroid hormone responses and uterine receptivity.

\section{Materials and methods}

\section{Animals}

All animal experiments were reviewed and approved by the Washington State University Institutional Animal Care and Use Committee. Prkaa1/2d/d mice were developed by crossing Prkaa1/2 fl/fl mice with Pgr-cre mice to conditionally ablate genes encoding the $\alpha 1$ and $\alpha 2$ catalytic domains of AMPK within the female reproductive tract (Soyal et al. 2005, McCallum et al. 2018). The exact genetic background of these mice is not known. However, based on the number of crosses we have made in our own lab, the mice are on a greater than $95 \%$ C57BL/6 background. The sub/infertility and faulty artificial decidualization observed in Prkaa $1 / 2^{d / d}$ female mice (McCallum et al. 2018) prompted us to further evaluate the conditional ablation of Prkaa1/2 during the time of uterine receptivity and early decidualization. We were also interested in comparing uterine steroid hormone responses in Prkaa 1/2 $2^{f / f l}$ and Prkaa $1 / 2^{d / d}$ female mice. For the early pregnancy studies, female mice were placed with males of proven breeding capacity and were considered day of pregnancy (DOP) 0.5 upon observation of a vaginal plug. Female reproductive tracts were collected for histological analyses on DOP4, 5 and 8. On DOP5, blood was collected from Prkaa 1/2flffl and Prkaa $1 / 2^{d / d}$ female mice for serum isolation and the mice were then immediately killed. Serum samples were submitted to the University of Virginia Center for Research in Reproduction Ligand Assay and Analysis Core for $\mathrm{P}_{4}$ hormone assays.

For evaluating uterine steroid hormone responses around the time of embryo implantation, 6-10 week old Prkaa1/2f/ffl and Prkaa $1 / 2^{d / d}$ female mice were bred by vasectomized male mice of proven breeding capacity to induce pseudopregnancy. On day of pseudopregnancy (DOPP4), a 0.5-inch 30 gauge needle was inserted entirely into the uterine lumen and a scratch was made when the needle was drawn back, as $25 \mu \mathrm{L}$ of sesame oil was injected into the uterine lumen to initiate decidualization. Uteri were collected $24 \mathrm{~h}$ later for mRNA isolation and histological evaluation. Ovaries were also collected and processed for paraffin embedding. This model relies on endogenous steroids to prime the uterus for decidualization. In a second pseudopregnancy model, we ovariectomized Prkaa $1 / 2^{f / f f l}$ and Prkaa $1 / 2^{d / d}$ female mice and allowed them to recover for 2 weeks. The mice were then given a steroid hormone regimen consistent with early pregnancy and artificially decidualized on the equivalent of DOPP4 (Zhang et al. 2012, McCallum et al. 
2018). Uteri from Prkaa1/2fl/fl and Prkaa1/2d/d female mice were collected $24 \mathrm{~h}$ later and processed for mRNA isolation and paraffin embedding.

\section{RNA isolation and quantitative polymerase chain reaction ( $q P C R)$}

Uterine expression of genes associated with receptivity and decidualization was determined by qPCR using primer sets identified in Table 1. For these studies, RNA was isolated from uteri obtained from Prkaa1/2fl/fl and Prkaa1/2d/d mice using Tri-Reagent (Sigma-Aldrich) following the manufacturer's instruction. Isolated RNA was DNase treated (Roche Applied Science) and quantified using a NanoDrop 2000 Spectrophotometer (Thermo Scientific) prior to cDNA synthesis. mRNA was then reverse transcribed using Bio-Rad iScript (Bio-Rad). Quantitative PCR was completed using BioRad's C1000 CFX96 Real-Time Thermal Cycler System with an annealing temperature of $56-58^{\circ} \mathrm{C}(1 \mathrm{~min})$ for 40 cycles. Data were analyzed with CFX Manager Software (Bio-Rad). Rp/13a was used as an internal control to normalize expression data. A no reverse transcriptase negative control was included to confirm the absence of genomic DNA.

\section{Immunohistochemistry}

All tissues were fixed in $4 \%$ paraformaldehyde and stored in $70 \%$ ethanol until paraffin embedding. Tissues were processed in an ethanol gradient and xylenes, embedded in paraffin and sectioned at $5 \mu \mathrm{m}$. Tissue sections were heated at $65^{\circ} \mathrm{C}$ for $60 \mathrm{~min}$ then deparaffinized in xylenes, rehydrated in a series of decreasing ethanol washes and placed in PBS. Slides were stained with hematoxylin and eosin (Scytek Laboratories Inc., Logan, UT) as per manufacturer's instructions or they were used for immunohistochemistry (IHC). For IHC, tissue sections underwent quenching (10 min in 3\% hydrogen peroxide) and antigen retrieval (brought to a boil in $0.1 \mathrm{M}$ sodium citrate followed by incubation in the heated solution for $20 \mathrm{~min}$ and then cooling to room temperature). Sections were then blocked $(0.1 \%$ BSA, $0.1 \%$ normal goat serum or normal donkey serum and $1 \%$ Triton-X100 in PBS) for $1 \mathrm{~h}$ and then incubated overnight at $4{ }^{\circ} \mathrm{C}$ in blocking solution containing primary antibody shown in Table 2 . Slides were washed in PBS $(3 \times 10 \mathrm{~min})$ and incubated with secondary antibody diluted at 1:500 in blocking solution for $30 \mathrm{~min}$ at room temperature. Sections were washed as before and then incubated with horseradish peroxidase-conjugated streptavidin (Vector Laboratories, Burlingame, CA). Washes were again performed and the sections were exposed to 3,3'-diaminobenzidine (BD Biosciences, San Diego, CA) followed by a 5-min inactivation in PBS. Sections were then counterstained with methyl green or hematoxylin, dehydrated and mounted.

\section{Statistical analysis}

Data are presented as a mean \pm S.E.M. for $n=3-8$ independent experiments in which one mouse represented one experimental replicate. The exact number of experimental replicates are

Table 1 Primers used for genotyping and qPCR.

\begin{tabular}{|c|c|c|}
\hline Gene & Forward primer & Reverse primer(s) \\
\hline \multicolumn{3}{|l|}{ qPCR } \\
\hline Alox15 & 5'-AGAGTGGCCACACCAAGATG-3' & 5'-GTAGACCGCTTCAGCACCAT-3' \\
\hline Bmp2 & 5'-ACGAGAAAAGCGTCAAGCCA-3' & 5'-CCAGTCATTCCACCCCACAT-3' \\
\hline Ccna2 & 5'-TAAGCCTTGTCTTGTGGACCT-3' & 5'-TGTCTCTGGTGGGTTGAGAAG-3' \\
\hline Ccnb1 & 5'-ACAACGGTGAATGGACACCA-3' & 5'-TCATGTGCTTTGTGAGGCCA-3' \\
\hline Ccnb2 & 5'-TGCСTGTCTCAGAAGGTGCT-3' & 5'-AGCGATGAACTTGGTACGGTT-3' \\
\hline Ccne1 & 5'-GTTACAGATGGCGCTTGCTC-3' & 5'-AGCCAGGACACAATGGTCAG-3' \\
\hline Ccne2 & 5'-CCAGTAACAGTCATCTCCTGGT-3' & 5'-AGTCGATGGCTAGAATGCACA-3' \\
\hline Ccnf & 5'-TTCCACGATGATGCACCCAA-3' & 5'-GTCAGCATAGCTCAGCACCT-3' \\
\hline Cdk1 & 5'-ACGGCGACTCAGAGATTGAC-3' & 5'-ACTTCTGGCCACACTTCGTT-3' \\
\hline$E 2 f 8$ & 5'-TAACGACATCTGCCTGGACG-3' & 5'-CCATGTGCAGGCTCTCTAGG-3' \\
\hline Esr1 & 5'-TGTTTGCTCCTAACTTGCTCCT-3' & 5'-TCATGCGGAACCGACTTGAC-3' \\
\hline Follistatin & 5'-GTGACAATGCCACATACGCC-3' & 5'-ACTTCAAGAAGCACGCCAGA-3' \\
\hline Gpx3 & 5'-CCGGGGACAAGAGAAGTCTAAG-3' & 5'-GATGGTGAGGGCTCCATACTC-3' \\
\hline Hand2 & 5'-TCAAGGCGGAGATCAAGAAGAC-3' & 5'-TTCTTGTCGTTGCTGCTCACT-3' \\
\hline$/ / 1 b$ & 5'-TGCCACCTTTTGACAGTGATGA-3' & 5'-ATCAGGACAGCCCAGGTCAA-3' \\
\hline $\operatorname{lnh} b b$ & 5'-TGTGGCACGAGAGACTCCTA-3' & 5'-CGCATCCGTTTGCTGGTATC-3' \\
\hline$L t f$ & 5'-CCTGCTTGCTAACCAGACCA-3' & 5'-ACACAGGGCACAGAGATTGG-3' \\
\hline Msx1 & 5'-CTAGATCGGACCCCGTGGAT-3' & 5'-TGGTCTTGTGCTTGCGTAGG-3' \\
\hline Muc1 & 5'-TACCACACTCACGGACGCTA-3' & 5'-ACTGCСАTTACСТGCCGAAA-3' \\
\hline Pgr & 5'-AGCATGTCGTCTGAGAAAGTGT-3' & 5'-AACACCGTCAAGGGTTCTCAT-3' \\
\hline $\operatorname{Prss} 28$ & 5'-CAАССТTCTCCAACGTGTGC-3' & 5'-TTGTGCTCGTCGGATGACTT-3' \\
\hline Rp/13a & 5'-TTGCTTACCTGGGGCGTCT-3' & 5'-ССТTTTССТTCСGTTTCTCСТC-3' \\
\hline S100a9 & 5'-ACCACCATCATCGACACCTTC-3' & 5'-AAAGGTTGCCAACTGTGCTTC-3' \\
\hline Tac2 & 5'-TAGCGTGGGACCAAAGGAGA-3' & 5'-GGCTGTTCСТCTTGCССАTA-3' \\
\hline \multicolumn{3}{|l|}{ Genotyping } \\
\hline \multirow[t]{2}{*}{ Pgr-Cre } & 5'-ATGTTTAGCTGGCCCAAATG-3' & 5'-TATACCGATCTCCCTGGACG-3' \\
\hline & & 5'-CCCAAAGAGACACCAGGAAG-3' \\
\hline Prkaa1 & 5'-TATTGCTGCCATTAGGCTAC-3' & 5'-GACCTGACAGAATAGGATATGCCCAACCTC-3' \\
\hline Prkaa2 & 5'-GCTTAGCACGTTACCCTGGATGG-3' & 5'-GTTATCAGCCCAACTAATTACAC-3' \\
\hline
\end{tabular}


Table 2 Antibodies used for IHC.

\begin{tabular}{llll}
\hline $\begin{array}{l}\text { Target } \\
\text { protein }\end{array}$ & $\begin{array}{l}\text { Manufacturer, Catalog } \\
\text { No. }\end{array}$ & $\begin{array}{l}\text { Species, } \\
\text { Clonal status }\end{array}$ & Dilution \\
\hline ESR1 & $\begin{array}{l}\text { Thermo Fisher } \\
\text { Scientific, MA5-13191 }\end{array}$ & $\begin{array}{l}\text { Mouse, } \\
\text { Monoclonal } \\
\text { Goat, Polyclonal }\end{array}$ & $1: 200$ \\
HAND2 & $\begin{array}{c}\text { Santa Cruz } \\
\text { Biotechnology, } \\
\text { SC-9409 }\end{array}$ & Rabbit, \\
PGR & $\begin{array}{c}\text { Monoclonal } \\
\text { RM-9102 }\end{array}$ & $1: 250$ \\
PHH3 & $\begin{array}{l}\text { Millipore, 06-570 } \\
\text { MUC1 }\end{array}$ & $\begin{array}{c}\text { Rabbit, Polyclonal } \\
\text { Rabbit, Polyclonal }\end{array}$ & $1: 500$ \\
$1: 100$
\end{tabular}

indicated in each figure legend. Animals were randomly assigned to each group based on genotype. Differences between treatment groups were analyzed using the Student's $t$-test. A $P$-value $\leq 0.05$ was considered significant. All data were analyzed using GraphPad Prism 5.0.

\section{Results}

We previously demonstrated that AMPK is required for fertility in the female and that uterine expression of $E_{2}$ (ESR1) and $P_{4}$ (PGR) receptors did not differ between Prkaa1/2flfl and Prkaa1/2d/d mice following $\mathrm{E}_{2}$ synchronization (McCallum et al. 2018). As $\mathrm{E}_{2}$ and $\mathrm{P}_{4}$ ensure that the uterus is receptive to the implanting embryo as pregnancy is established, we first evaluated the expression of Esr 1 and Pgr on DOPP5 by qPCR. A significant increase in Esr 1 mRNA levels were observed in the Prkaa1/2d/d uterus compared to the Prkaa1/2fl/fl uterus, whereas Pgr mRNA levels did not differ (Fig. 1A


Figure 1 Disrupted ESR1, but not PGR, expression in the DOPP5 Prkaa $1 / 2^{d / d}$ uterus. Shown are uterine RT-qPCR (A, B) and immunohistochemical (C) expression data for ESR1 and PGR on day of pseudopregnancy (DOPP) 5 in Prkaa $1 / 2^{f l / f l}$ and Prkaa $1 / 2^{d / d}$ mice. Values are expressed as mean \pm S.E.M., ${ }^{*} P \leq 0.05, n=4$. and B). This difference in Esr1 expression at the mRNA level was also evident at the protein level based on IHC analysis, particularly in the epithelial compartment (Fig. 1C).

In evaluating our prior breeding trial data (McCallum et al. 2018), we noted that the time to first weaning for nulliparous Prkaa1/2 d/d female mice was about twice that of female Prkaa $1 / 2^{f l f l}$ mice (Fig. 2A). Many of the pups born to Prkaa $1 / 2^{d / d}$ female mice appeared smaller at birth than pups from Prkaa $1 / 2^{f l / f l}$ female mice and this translated to a smaller mean pup mass at the time of weaning (Fig. 2B). Evaluation of ovaries from Prkaa 1/2 fl/fl and Prkaa 1/2 ${ }^{d / d}$ mice on DOP5
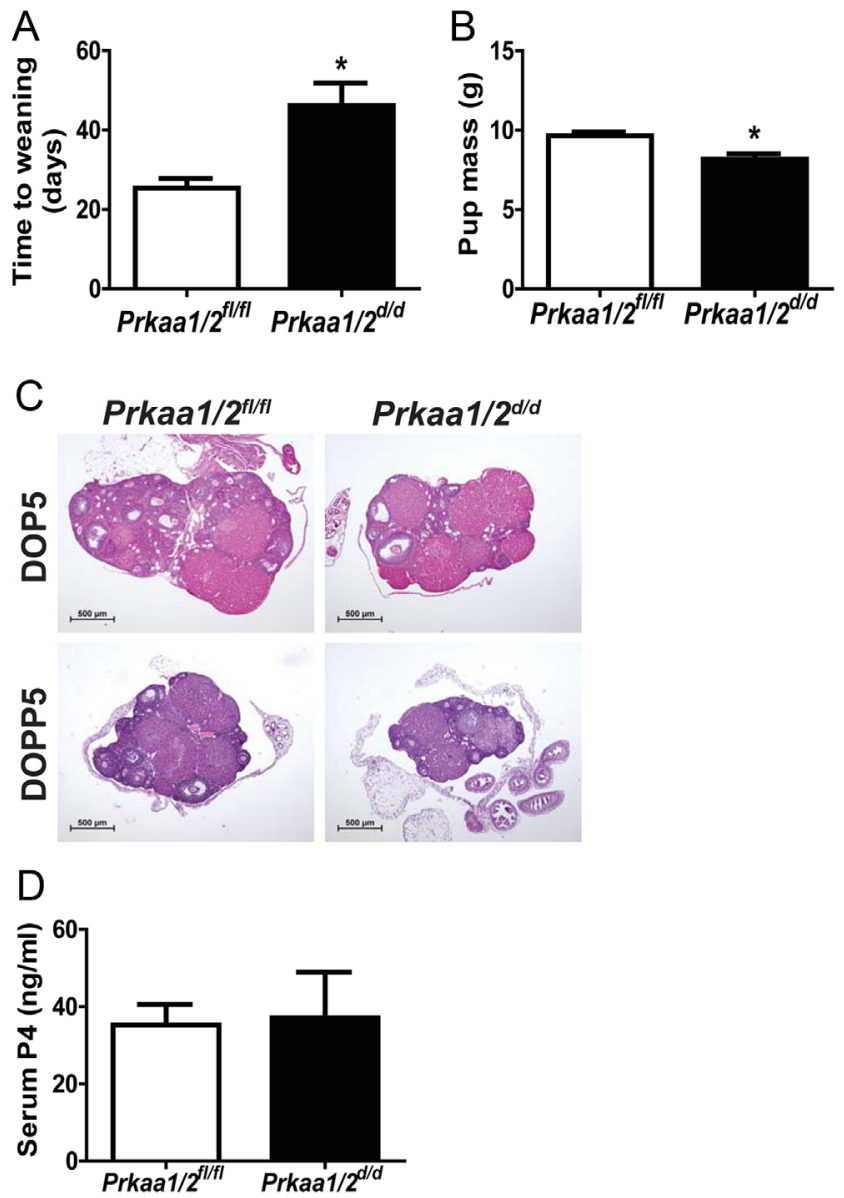

Figure 2 PRKAA1 and PRKAA2 deficiency disrupt time to first weaning with no impact on ovarian structure and function. (A) Overall time to weaning of pups is dramatically increased in primiparous Prkaa 1/2 d/d females $(P=0.014)$. (B) Pups born to Prkaa $1 / 2^{d / d}$ dams weighed significantly less at the time of weaning than pups born out of Prkaa1/2fl/fl females. (C) A histological analysis demonstrated no difference in ovarian architecture or corpora lutea formation between Prkaa1/2fl/fl and Prkaa 1/2 ${ }^{d / d}$ mice during early pregnancy (DOP5) or pseudopregnancy (DOPP5) $(n=4-6)$. (D) Serum $\mathrm{P}_{4}$ measured on DOP5 was not different between Prkaa 1/2 $2^{f / f l}$ $(n=6)$ and Prkaa $1 / 2^{d / d}(n=4)$ animals, demonstrating that postovulatory steroidogenesis is not dependent on AMPK activity. Values are expressed as mean \pm S.E.M., $* P \leq 0.05$. 
and DOPP5 revealed no histological differences (Fig. 2C). Furthermore, serum $\mathrm{P}_{4}$ levels were not different on DOP5 (Fig. 2D). Despite no difference in ovarian histology or luteal function, we observed faulty embryo implantation and embryonic growth in Prkaa 1/2 ${ }^{d / d}$ dams on DOP4, DOP5 and DOP8 (Fig. 3). Embryos within uteri from Prkaa $1 / 2^{d / d}$ mice were commonly not implanting (DOP4) or were smaller in size or degenerate (DOP4, DOP5 and DOP8) compared with embryos in uteri from Prkaa1/2fl/fl mice. Interestingly, while the initiation of stromal cell decidualization was visible in Prkaa1/2fl/fl mice on DOP4 and DOP5, the decidualization response was commonly blunted or absent during these times in Prkaa $1 / 2^{d / d}$ mice. Furthermore, the zippering of the luminal epithelium on DOP5 was often incomplete in Prkaa $1 / 2^{d / d}$ mice.

At the time of embryo apposition and implantation, endometrial epithelial cells should be non-proliferative and the underlying stromal cells should be proliferating in response to luteal-derived $\mathrm{P}_{4}$. In this next experiment, we generated pseudopregnant Prkaa $1 / 2^{f / / f l}$ and Prkaa1/2d/d mice by placing intact females with vasectomized male

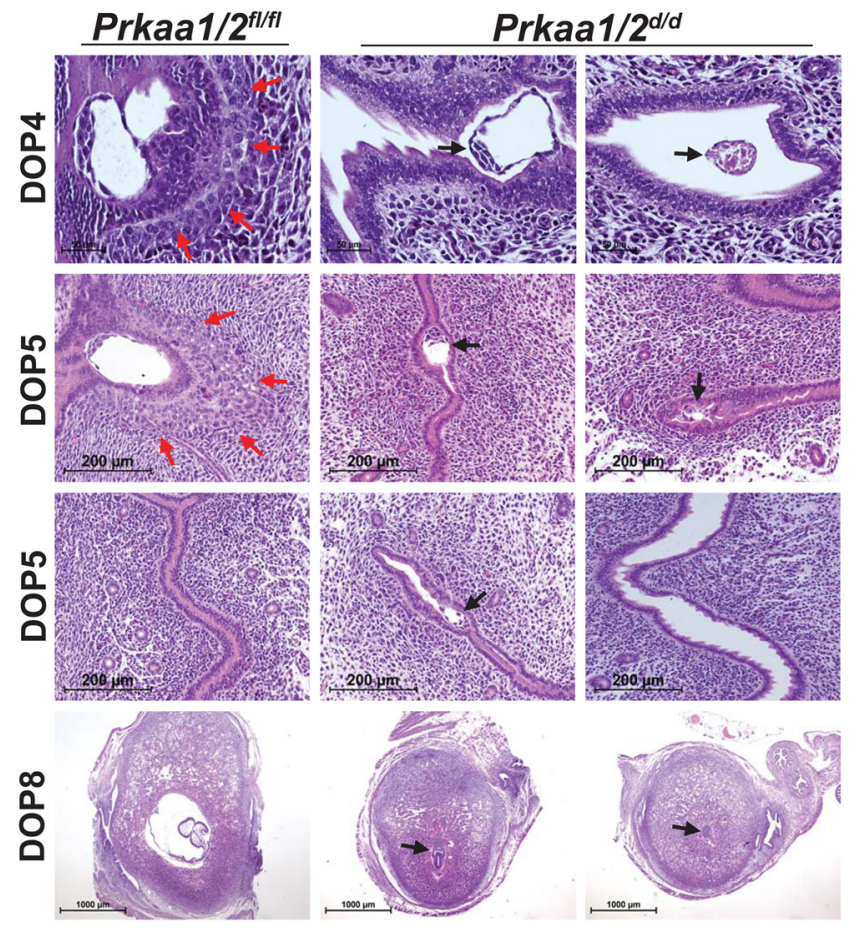

Figure 3 Embryo implantation is delayed or disrupted in Prkaa1/2d/d mice. Embryos from Prkaa $1 / 2^{f / f l}$ females implanted normally and the stroma decidualized as expected on DOP4, DOP5 and DOP8 (red arrows). Embryos from Prkaa1/2d/d females commonly failed to implant properly, were smaller in size or did not survive the implantation process (black arrows). The luminal epithelium of gravid Prkaa $1 / 2^{d / d}$ female mice failed to zipper shut on DOP5. While DOP8 embryos had greatly expanded in Prkaa $1 / 2^{f / f l}$ mice with a clear presence of an amniotic cavity, DOP8 embryos from Prkaa 1/2 ${ }^{d / d}$ mice were often small and stunted in development with reduced decidual expansion. $n=4-8$. mice to evaluate endometrial cell proliferation. While uteri from Prkaa $1 / 2^{f \mid f f}$ mice displayed normal endometrial cell proliferation, epithelia of Prkaa $1 / 2^{d / d}$ mice remained proliferative and the stromal cell compartment showed a significant decrease in proliferation on DOPP5 based on expression of the mitosis marker phospho-histone H3 (Fig. 4). This was accompanied by a significant decrease in the expression of the cell cycle regulatory genes Cyclin A2 (Ccna2), Cyclin B1 (Ccnb1), Cyclin B2 (Ccnb2), Cyclin E1 (Ccne1), Cyclin E2 (Ccne2), Cyclin F (Ccnf) and Cyclin Dependent Kinase 1 (Cdk1) (Fig. 5A) and the decidualization marker genes Follistatin (Fst), Inhibin $\beta B($ Inhbb), Bone morphogenetic protein 2 (Bmp2), heart-and neural crest derivatives-expressed protein 2 (Hand2), S100 calcium-binding protein A9 (S100a9) and serine protease 28 (Prss28) in Prkaa1/2d/d mice (Fig. 5B). Interestingly, wingless-type MMTV family member 4 (Wnt4), which is also essential for decidualization, was not differentially regulated. Three common $\mathrm{E}_{2}$-induced genes were up-regulated in uteri of Prkaa1/2 ${ }^{d / d}$ mice and these include Msh homeobox 1 (Msx1), Mucin 1 (Muc1) and Lactotransferrin (Ltf, $P=0.07$ ) (Fig. 5C). Several other genes such as Tachykinin 2 (Tac2), E2F transcription factor 8 (E2f8), Glutathione peroxidase 3 (Gpx3), Arachidonate 15-lipoxygenase (Alox15) and Interleukin 1 beta (IL1b) were also

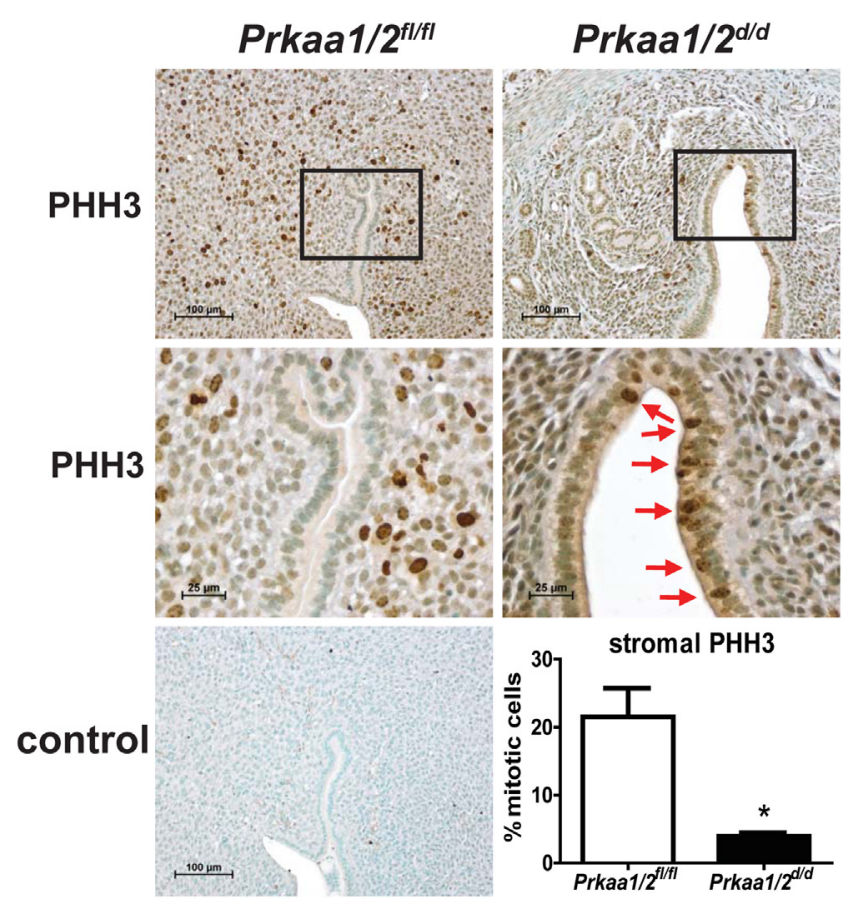

Figure 4 Aberrant retention of luminal epithelial proliferation and decreased stromal proliferation in the DOPP5 Prkaa $1 / 2^{d / d}$ uterus. Immunohistochemical staining for the mitosis marker phosphohistone- $\mathrm{H} 3(\mathrm{PHH})$ shows retention of luminal epithelial proliferation in the DOPP5 Prkaa $1 / 2^{d / d}$ uterus with significantly diminished proliferation in the stromal compartment compared to the Prkaa $1 / 2^{f l / f l}$ uterus $(* P=0.02)$. Values are expressed as mean \pm S.E.M., $n=3-4$. 

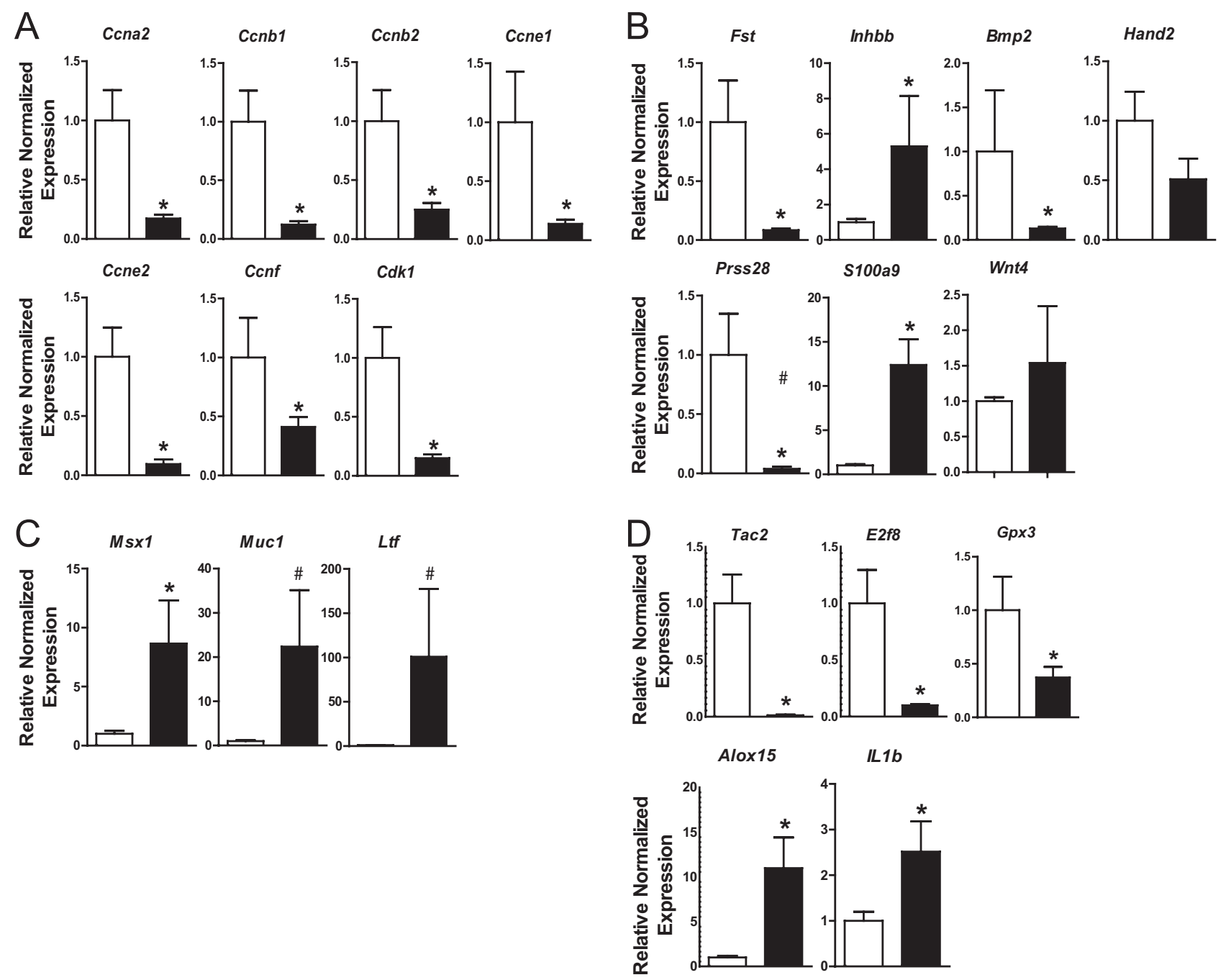

Figure 5 PRKAA1 and PRKAA2 deficiency results in differential expression of genes associated with the cell cycle, decidualization, estrogensignaling and inflammation on DOPP5. Using an intact pseudopregnancy model, RT-qPCR was used to evaluate expression of cell cycle regulatory genes Ccna2, Ccnb1, Ccnb2, Ccne1, Ccne2, Ccnf and Cdk1 (A) and genes important for decidualization (B; Fst, Inhbb, Bmp2, Hand2, S100a9, Prss28 and Wnt4) in uteri obtained from Prkaa 1/2 $2^{\mathrm{fl} / \mathrm{fl}}$ (white bars) and Prkaa 1/2 ${ }^{\mathrm{d} / \mathrm{d}}$ (black bars) mice. $\mathrm{E}_{2}$ responsive genes (C; Msx1, Muc1 and Ltf), as well as genes commonly associated with inflammation (D; Tac2, E2f8, Gpx3, Alox15 and IL1b) were also differentially regulated between groups. Values are expressed as mean \pm S.E.M., ${ }^{*} P \leq 0.05 ;{ }^{*} P=0.07, n=3$.

differentially expressed (Fig. 5D; Qi et al. 2015, Xu et al. 2014). The Hand2 gene is fundamentally required for uterine receptivity and decidualization in mice (Li et al. 2011). Evaluation of HAND2 protein expression by IHC revealed a significant decrease in stromal cell expression at a time when decidualization should be just underway (Fig. 6). These cumulative findings are consistent with the failure of uteri from Prkaa $1 / 2^{d / d}$ mice to undergo artificial decidualization (McCallum et al. 2018) and for faulty embryo implantation and luminal closure in these mice, and these defective uterine functions may stem from elevated or unopposed $\mathrm{E}_{2}$-regulated signaling.

To provide additional evidence that uteri from Prkaa $1 / 2^{d / d}$ mice fail to properly respond to steroid hormones and establish a receptive uterus, we ovariectomized Prkaa1/2 $2^{f / f l}$ and Prkaa1/2 ${ }^{d / d}$ mice, provided an exogenous steroid hormone regimen consistent with early pregnancy (McCallum et al. 2018) and then evaluated cell proliferation and gene expression on DOPP5 as before. Unlike uteri from Prkaa $1 / 2^{f l / f l}$ mice, uteri from Prkaa $1 / 2^{d / d}$ mice retained mitotic epithelial cells and tended $(P=0.07)$ to weigh more than uteri from Prkaa 1/2 ${ }^{f / f l}$ mice (Fig. 7). Likewise, we observed the same differential expression for Fst, Inhbb, Muc1, Alox 15 and Tac2 as we did in intact mice that were exposed to endogenous steroid hormones.

\section{Discussion}

We previously established an essential role for the AMPK signal transduction pathway in uterine physiology (McCallum et al. 2018). Ablation of 


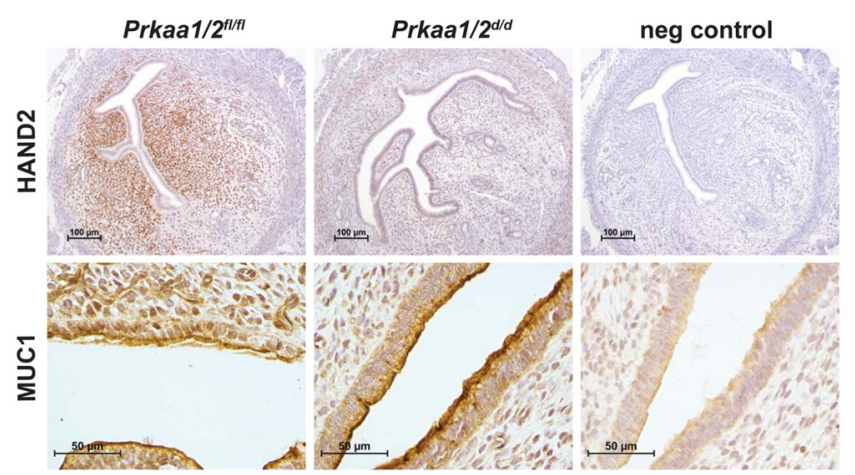

Figure 6 HAND2 expression is decreased in the DOPP5 Prkaa1/2 d/d uterus. HAND2 and MUC1 were evaluated in intact Prkaa $1 / 2^{f / f l}$ and Prkaa $1 / 2^{d / d}$ mice on DOPP5 using immunohistochemistry. Prkaa $1 / 2^{f l /}$ ${ }^{f l}$ animals show strong expression of HAND2 in the stroma, whereas Prkaa $1 / 2^{d / d}$ animals show a dramatic decrease in stromal staining. No difference in MUC1 expression was observed between the two groups. $n=3$.

genes encoding the $\alpha 1$ and $\alpha 2$ catalytic subunits of AMPK from the female reproductive tract resulted in subfertility that rapidly progressed to complete infertility. Associated features of this broad phenotype included faulty decidualization, parturition-dependent fibrosis of the stromal compartment (i.e. endometritis) and chronic inflammation. It was noted from breeding trial data that the time to first weaning of pups born to Prkaa $1 / 2^{d / d}$ dams was twice as long as that observed for Prkaa $1 / 2^{f l / f l}$ dams despite no difference in estrous cyclicity. Pups born to Prkaa $1 / 2^{d / d}$ dams were also smaller at the time of weaning, suggesting additional functions for AMPK during pregnancy beyond those previously described (McCallum et al. 2018). As such, the objective of the present study was to evaluate the role of AMPK in establishing the uterine receptive state during early pregnancy. In addition to evaluating early pregnancy, we used two models to appraise AMPK functions around the time of uterine receptivity. The first involved use of intact Prkaa1/2fl/fl and Prkaa1/2 ${ }^{d / d}$ mice that were bred to vasectomized male mice to induce a state of pseudopregnancy. This model relies on endogenous steroid hormones to develop the receptive endometrium. The second model used Prkaa1/2fl/fl and Prkaa1/2 ${ }^{d / d}$ mice that were first ovariectomized and then given a series of daily steroid hormone injections that mimicked early pregnancy. Even though estrous cyclicity and steroidogenesis were not different between intact Prkaa $1 / 2^{f / / f l}$ and Prkaa $1 / 2^{\mathrm{d} / d}$ mice (McCallum et al. 2018, Fig. 2), and a histological evaluation of ovaries on DOP5 and DOPP5 collectively indicated that Prkaa1/2 are dispensable for normal ovarian functions (McCallum et al. 2018, Fig. 2), this second model was implemented to directly evaluate the effects of steroid hormone actions on the uterus under controlled conditions.
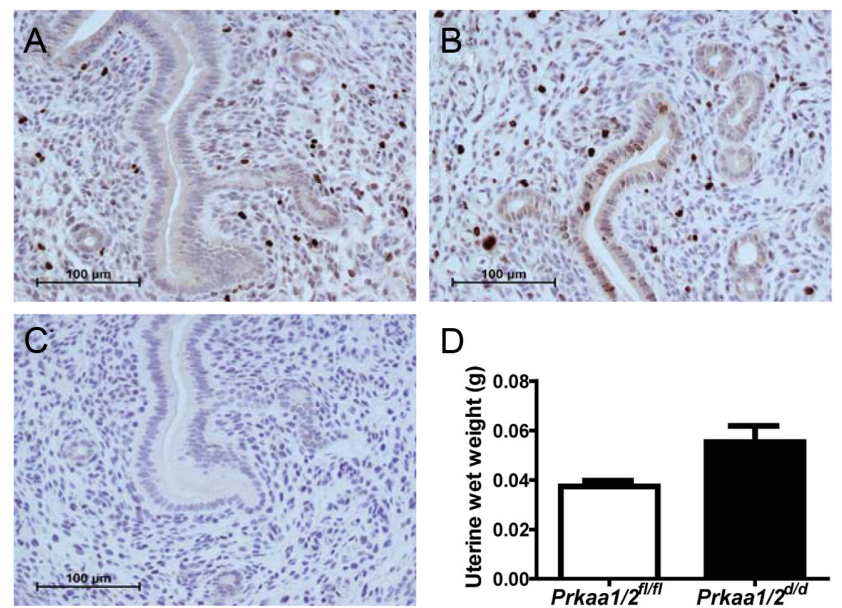

E

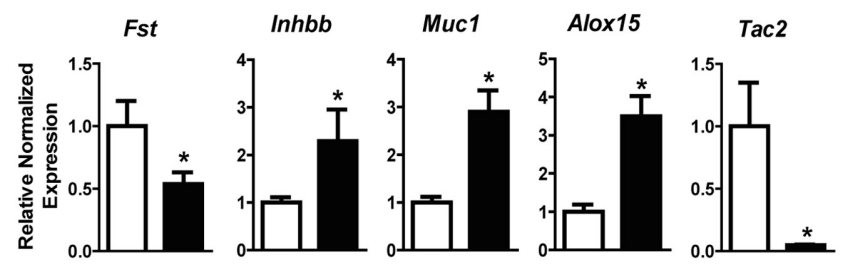

Figure 7 Aberrant steroid hormone signaling in uteri from ovariectomized Prkaa1/2 $2^{d / d}$ mice treated with exogenous steroid hormones mimicking early pregnancy. (A) Following ovariectomy and provision of a steroid hormone regimen consistent with early pregnancy (McCallum et al. 2018), immunohistochemical analysis of the mitosis marker phosphohistone-H3 shows some proliferation in the stromal compartment with no proliferation in the luminal epithelium in Prkaa 1/2 fl/fl uteri. (B) In contrast, Prkaa1/2d/d uteri show retention of proliferation in the luminal epithelium with some proliferation in the stroma. (C) No primary antibody negative control. (D) Prkaa $1 / 2^{d / d}$ uteri tended $(P=0.07)$ to weigh more than Prkaa $1 / 2^{f / f t}$ uteri. (E) RT-qPCR analysis of Fst, Inhbb, Muc1, Alox15 and Tac2 in uteri obtained from Prkaa $1 / 2^{f / f l}$ and Prkaa $1 / 2^{d / d}$ mice. Values are expressed as mean \pm S.E.M., $* P \leq 0.05, n=3$.

Uterine receptivity is established in response to the synchronous secretion of ovarian-derived $E_{2}$ and $P_{4}$. These two steroid hormones work in series with $E_{2}$ first priming the endometrium to undergo epithelial cell proliferation. This is followed by $\mathrm{P}_{4}$, which attenuates epithelial cell proliferation causing them to take on a differentiated secretory function and stimulating stromal cell proliferation (Das \& Martin 1973, Wang \& Dey 2006). In addition to appropriately timed ligand availability, uterine expression of the classical receptors for $\mathrm{E}_{2}$ and $\mathrm{P}_{4}$ are tightly regulated. Dysregulation of these receptors compromises fertility in the female. Whereas ESR1 expression normally decreases during the window of implantation (Lessey et al. 2006), an increase in ESR1 mRNA and protein was observed in uteri from Prkaa $1 / 2^{d / d}$ mice during the window of implantation. 
Elevated ESR1 expression in the endometrium of women during the window of implantation is implicated in some cases of unexplained infertility (Lessey et al. 2006, Dorostghoal et al. 2018).

Because of the increased expression of ESR1 during receptivity, we evaluated implantation and early embryo development on DOP4, 5 and 8. Murine implantation occurs between DOP4 and DOP5. Absorption of uterine fluid and closure, or zippering, of the luminal epithelium promote proper antimesometrial eccentric implantation in mice (Zhang et al. 2013). We previously noted upon gross observation that implantation sites from 4 to 6-month-old nulliparous Prkaa $1 / 2^{d / d}$ mice appear normal. However, upon histological evaluation of implantation sites at the time of embryo implantation (i.e. DOP 4 and 5; Fig. 3) in 6-10 week-old Prkaa1/2d/d mice, we did observe clear signs of an unzippered luminal epithelium, lack of formation of an embryonic chamber and stunted embryonic growth in some sites, all of which are clear signs of dyssynchrony between the mother and implanting embryo. While exhibiting the same gestation length, the delay in implantation likely explains the decrease in pup mass observed in offspring born to Prkaa1/2d/d mice. Use of the Pgr-cre mouse results in peri-ovulatory ablation of floxed genes in ovarian follicles and subsequent corpora lutea, given that $\mathrm{Pgr}$ is normally expressed for a 12 -h window on either side of ovulation in mice. Despite peri-ovulatory follicular ablation of Prkaa1 and Prkaa2, ovulation, luteinization and $\mathrm{P}_{4}$ steroidogenesis were normal in Prkaa1 $1 / 2^{d / d}$ mice. In support of our previous findings (McCallum et al. 2018), these data suggest that AMPK is dispensable for late follicular and luteal functions in the ovary and that early pregnancy issues observed in Prkaa $1 / 2^{d / d}$ mice most likely derive from disrupted uterine functions.

To characterize the faulty uterine receptivity phenotype in more detail, we next evaluated steroid hormone-induced proliferation in the epithelial and stromal compartments, as well as expression of markers of stromal decidualization and inflammation in both models of pseudopregnancy. Coupled with elevated expression of ESR 1 in uteri obtained from Prkaa1/2d/d mice on DOPP5 was the prolonged retention of luminal epithelial cell mitosis and elevated expression of the $\mathrm{E}_{2}$ marker genes Msx1, Muc1 and Ltf. While Msx1 expression normally increases in epithelial tissue on DOP4 in the receptive mouse uterus, its expression is almost undetectable following implantation or the equivalent time during pseudopregnancy (Daikoku et al. 2011). Msx 1 is fundamentally required for establishing the receptive state in mice through its modulation of epithelial junctional activity in luminal tissue (Sun et al. 2016). Msx 1 expression was more recently shown to be widely disrupted in infertile women, where reduced Msx 1 expression associated with loss of epithelial cell polarity and a receptive uterine state. (Bolnick et al. 2016).
Within the stromal compartment, a five-fold decrease in stromal cell proliferation was also observed in DOPP5 Prkaa $1 / 2^{d / d}$ uteri, a phenotype that was accompanied by down-regulation of several cell cycle regulatory genes. This likely contributed to faulty artificial decidualization (McCallum et al. 2018) and the diminished size of implantation sites during early pregnancy (Fig. 3). We also noted that decreased expression of decidualization markers, a number of which are discussed subsequently, have been shown through mutagenesis studies in mice and knockdown studies in human endometrial stromal cells to be essential for decidualization. Bone morphogenetic protein 2 (Bmp2), follistatin (Fst) and heart- and neural crest derivatives-expressed protein 2 (Hand2) are among the most well-studied (Lee et al. 2007, Li et al. 2013, Bhurke et al. 2016, Fullerton et al. 2017). The Prkaa $1 / 2^{d / d}$ uterine phenotype is strikingly similar to the Fst conditional mutant phenotype in which uterine ablation of Fst resulted in subfertility caused by a failure to achieve uterine receptivity, retention of features of $E_{2}$ signaling, such as luminal epithelial cell proliferation at a time when $\mathrm{P}_{4}$ signaling should dominate, impaired embryo implantation, and faulty decidualization (Fullerton et al. 2017). Another interesting feature of the $F s t^{d / d}$ phenotype is the increased expression of inhibin $\beta B$. When dimerized, inhibin $\beta B$ forms activin, which in turn antagonizes BMP signaling. Importantly, BMP signaling, particularly that initiated by BMP2 and BMP7 (Lee et al. 2007, Li et al. 2013, Monsivais et al. 2017), is an essential component of the differentiation program that establishes the receptive state and initiates decidualization in the uterus. The Prkaa $1 / 2^{d / d}$ uterus similarly shows a pattern of decreased Fst and increased Inhbb during receptivity (Fig. 5b). We suspect that AMPK signaling is essential for reducing Inhbb expression, which then ensures robust BMP signaling that is necessary for initiating the deciduogenic response. The decreased expression of Hand 2 mRNA was validated at the protein level by immunohistochemistry. This protein is a mediator of the antiproliferative action of $\mathrm{P}_{4}$ ( $\mathrm{Li}$ et al. 2011). The significant decrease in HAND2 expression in the Prkaa $1 / 2^{d / d}$ uterus likely contributes to aberrantly retained epithelial cell expression during receptivity. Of note, the expression of Wnt4, another essential gene required for decidualization, was not different in uterine tissues isolated from Prkaa1/2fl/fl and Prkaa1/2d/d mice. This indicates that AMPK, either directly or indirectly, is necessary for mediating steroid hormone regulated expression of a select cadre of genes essential for implantation and decidualization, but not others.

In summary, this study demonstrates the functional requirement of AMPK signaling in establishing the uterine receptive state for embryo implantation. The actions of AMPK are commonly associated with sensing and regulating available cellular energy. While we have not ruled out the possibility that pregnancy issues observed in Prkaa1/2 d/d mice stem specifically 
from faulty energy sensing, we do show that aberrant expression of $E_{2}$ responsive genes, as well as genes that coordinate stromal decidualization, strongly support the idea that AMPK is functionally linked to normal steroid hormone signaling in the uterus. What now remains to be determined is: (1) to identify the factor(s) that increase AMPK signaling prior to transitioning to the receptive state; and (2) determine the molecular mechanism by which AMPK differentially regulates $\mathrm{E}_{2^{-}}$and $\mathrm{P}_{4}$-dependent genes. With regard to identifying factors that increase AMPK signaling, AMPK activity was recently shown to increase in human stromal cell decidualization assays in an EGF receptor-dependent fashion (Large et al. 2014.) As EGFR and several EGF-like ligands (e.g. HB-EGF, amphiregulin) have been shown to be important for implantation and decidualization (Das et al. 1994, 1995, Leach et al. 1999, Paria et al. 2001, Large et al. 2014), this would place AMPK near the top of the molecular pyramid that controls establishment of the receptive state should AMPK be confirmed as one of the phosphorylation cascades downstream of the EGFR.

\section{Declaration of interest}

The authors declare that there is no conflict of interest that could be perceived as prejudicing the impartiality of the research reported.

\section{Funding}

The authors thank The University of Virginia Center for Research in Reproduction Ligand Assay and Analysis Core, supported by the Eunice Kennedy Shriver NICHD/NIH P50 grant (HD28934), for performing the serum $\mathrm{P}_{4}$ hormone assays. The authors are grateful for funding support from the National Institutes of Health (HD086402 to J K P and HD097087 to W W).

\section{Author contribution statement}

R M G, C A P, S K B, A R C and J K P conceived the project, designed the experiments and analyzed data. R M G, C A P, $S K B, M L M, N C K, W W$ and T E S performed gene and protein expression studies. R M G, C A P and J K P wrote the manuscript and integrated comments from other authors.

\section{References}

Banek CT, Bauer AJ, Needham KM, Dreyer HC \& Gilbert JS 2013 AICAR administration ameliorates hypertension and angiogenic imbalance in a model of preeclampsia in the rat. American Journal of Physiology: Heart and Circulatory Physiology 304 H1159-H1165. (https://doi.org/10.1152/ ajpheart.00903.2012)

Bertoldo MJ, Faure M, Dupont J \& Forment P 2015 AMPK: a master energy regulator for gonadal function. Frontiers in Neuroscience 9 235. (https:// doi.org/10.3389/fnins.2015.00235)

Bhurke AS, Bagchi IC \& Bagchi MK 2016 Progesterone-regulated endometrial factors controlling implantation. American Journal of Reproductive Immunology 75 237-245. (https://doi.org/10.1111/ aji.12473)
Bigham AW, Julian CG, Wilson MJ, Vargas E, Browne VA, Shriver MD \& Moore LG 2014 Maternal PRKAA1 and EDNRA genotypes are associated with birth weight, and PRKAA1 with uterine artery diameter and metabolic homeostasis at high altitude. Physiological Genomics 46 687-697. (https://doi.org/10.1152/physiolgenomics.00063.2014)

Bolnick AD, Bolnick JM, KIlburn BA, Stewart T, Oakes J, RodriguezKovacs J, Kohan-Ghadr HR, Dai J, Diamond MP, Hirota Y et al. 2016 Reduced homeobox protein MSX1 in human endometrial tissue is linked to infertility. Human Reproduction 31 2042-2050. (https://doi. org/10.1093/humrep/dew143)

Carey EA, Albers RE, Doliboa SR, Hughes M, Wyatt CN, Natale DR \& Brown TL 2014 AMPK knockdown in placental trophoblast cells results in altered morphology and function. Stem Cells and Development 23 2921-2930. (https://doi.org/10.1089/scd.2014.0092)

Cheng JG, Chen JR, Hernandez L, Alvord WG \& Stewart CL 2001 Dual control of LIF expression and LIF receptor function regulate Stat3 activation at the onset of uterine receptivity and embryo implantation. PNAS 98 8680-8685. (https://doi.org/10.1073/pnas.151180898)

Cheng J, Rosario G, Cohen TV, Hu J \& Stewart CL 2017 Tissue-specific ablation of the LIF receptor in the murine uterine epithelium results in implantation failure. Endocrinology 158 1916-1928. (https://doi. org/10.1210/en.2017-00103)

Daikoku T, Cha J, Sun X, Tranguch S, Xie H, Fujita T, Hirota Y, Lydon J, DeMayo F, Maxson R et al. 2011 Conditional deletion of Msx homeobox genes in the uterus inhibits blastocyst implantation by altering uterine receptivity. Developmental Cell 21 1014-1025. (https://doi. org/10.1016/j.devcel.2011.09.010)

Das RM \& Martin L 1973 Progesterone inhibition of mouse uterine epithelial proliferation. Journal of Endocrinology 59 205-206. (https:// doi.org/10.1677/joe.0.0590205)

Das SK, Wang XN, Paria BC, Damm D, Abraham JA, Klagsbrun M, Andrews GK \& Dey SK 1994 Heparin-binding EGF-like growth factor gene is induced in the mouse uterus temporally by the blastocyst solely at the site of its apposition: a possible ligand for interaction with blastocyst EGF-receptor in implantation. Development 120 1071-1083.

Das SK, Chakraborty I, Paria BC, Wang XN, Plowman G \& Dey SK 1995 Amphiregulin is an implanation-specific and progesterone-regulated gene in the mouse uterus. Molecular Endocrinology 9 691-705. (https:// doi.org/10.1210/mend.9.6.8592515)

Deng W, Cha J, Yuan J, Haraguchi H, Bartos A, Leishman E, Viollet B, Bradshaw HB, Hirota Y \& Dey SK 2016 p53 coordinates decidual sestrin 2/AMPK/mTORC1 signaling to govern parturition timing. Journal of Clinical Investigation 126 2941-2954. (https://doi.org/10.1172/JCl87715)

Dorostghoal M, Ghaffari HO, Marmazi F \& Keikhah N 2018 Overexpression of endometrial estrogen receptor-alpha in the window of implantation in women with unexplained infertility. International Journal of Fertility and Sterility 12 37-42. (https://doi.org/10.22074/ijfs.2018.5118)

Fullerton PT, Monsivais D, Kommagani R \& Matzuk MM 2017 Follistatin is critical for mouse uterine receptivity and decidualization. PNAS $\mathbf{1 1 4}$ E4772-E4781. (https://doi.org/10.1073/pnas.1620903114)

Hardie DG \& Lin SC 2017 AMP-activated protein kinase - not just an energy sensor. F1000Research 6 1724. (https://doi.org/10.12688/ f1000research.11960.1)

Hardie DG, Hawley SA \& Scott JW 2006 AMP-activated protein kinase development of the energy sensor concept. Journal of Physiology $\mathbf{5 7 4}$ 7-15. (https://doi.org/10.1113/jphysiol.2006.108944)

Horman S, Beauloye C, Vanoverschelde JL \& Bertrand L 2012 AMPactivated protein kinase in the control of cardiac metabolism and remodeling. Current Heart Failure Reports 9 164-173. (https://doi. org/10.1007/s11897-012-0102-z)

Jansson N, Rosario FJ, Gaccioli F, Lager S, Jones HN, Roos S, Jansson T \& Powell TL 2013 Activation of placental mTOR signaling and amino acid transporters in obese women giving birth to large babies. Journal of Clinical Endocrinology and Metabolism 98 105-113. (https://doi. org/10.1210/jc.2012-2667)

Kaufman MR \& Brown TL 2016 AMPK and placental progenitor cells. Experientia Supplementum 107 73-79. (https://doi.org/10.1007/978-3319-43589-3_4)

Kim ST \& Moley KH 2009 Regulation of facilitative glucose transporters and AKT/MAPK/PRKAA signaling via estradiol and progesterone in the mouse uterine epithelium. Biology of Reproduction 81 188-198. (https:// doi.org/10.1095/biolreprod.108.072629) 
Large MJ, Wetendorf M, Lanz RB, Hartig SM, Creighton CJ, Mancini MA, Kovanci E, Lee KF, Threadquill DW, Lydon JP et al. 2014 The epidermal growth factor receptor critically regulates endometrial function during early pregnancy. PLoS Genetics 10 e1004451. (https://doi.org/10.1371/ journal.pgen.1004451)

Leach RE, Khalifa R, Ramirez ND, Das SK, Wang J, Dey SK, Romero R \& Armant DR 1999 Multiple roles for heparin-binding epidermal growth factor-like factor are suggested by its cell-specific expression during the human endometrial cycle and early placentation. Journal of Clinical Endocrinology and Metabolism 84 3355-3363. (https://doi.org/10.1210/ jcem.84.9.5980)

Lee KY, Jeong JW, Wang J, Ma L, Martin JF, Tsai SY, Lydon JP \& DeMayo FJ 2007 Bmp2 is critical for the murine uterine decidual response. Molecular and Cellular Biology 27 5468-5478. (https://doi.org/10.1128/ MCB.00342-07)

Lessey BA, Palomino WA, Apparao KB, Young SL \& Lininger RA 2006 Estrogen receptor-alpha (ER-alpha) and defects in uterine receptivity in women. Reproductive Biology and Endocrinology 4 S9. (https://doi. org/10.1186/1477-7827-4-S1-S9)

Li Q, Kannan A, DeMayo FJ, Lydon JP, Cooke PS, Yamagishi H, Srivastava D, Bagchi MK \& Bagchi IC 2011 The antiproliferative action of progesterone in uterine epithelium is mediated by Hand2. Science 331 912-916. (https://doi.org/10.1126/science.1197454)

Li Q, Kannan A, Das A, Demayo FJ, Hornsby PJ, Young SL, Taylor RN, Bagchi MK \& Bagchi IC 2013 WNT4 acts downstream of BMP2 and functions via beta-catenin signaling pathway to regulate human endometrial stromal cell differentiation. Endocrinology 154 446-457. (https://doi.org/10.1210/en.2012-1585)

Lim R, Barker G \& Lappas M 2015 Activation of AMPK in human fetal membranes alleviates infection-induced expression of pro-inflammatory and pro-labour mediators. Placenta 36 454-462. (https://doi. org/10.1016/j.placenta.2015.01.007)

Makker A, Goel MM, Nigam D, Mahdi AA, Das V, Agarwal A, Pandey A \& Gautam A 2018 Aberrant Akt activation during implantation window in infertile women With intramural uterine fibroids. Reproductive Sciences 25 1243-1253. (https://doi.org/10.1177/1933719117737844)

Martino J, Sebert S, Segura MT, Garcia-Valdes L, Florido J, Padilla MC, Marcos A, Rueda R, McArdle HJ, Budge H et al. 2016 Maternal body weight and gestational diabetes differentially influence placental and pregnancy outcomes. Journal of Clinical Endocrinology and Metabolism 101 59-68. (https://doi.org/10.1210/jc.2015-2590)

Mayes MA, Laforest MF, Guillemette C, Gilchrist RB \& Richard FJ 2007 Adenosine 5'-monophosphate kinase-activated protein kinase (PRKA) activators delay meiotic resumption in porcine oocytes. Biology of Reproduction 76 589-597. (https://doi.org/10.1095/ biolreprod.106.057828)

McCallum ML, Pru CA, Smith AR, Kelp NC, Foretz M, Viollet B, Du M \& Pru JK 2018 A functional role for AMPK in female fertility and endometrial regeneration. Reproduction 156 501-513. (https://doi. org/10.1530/REP-18-0372)

Monsivais D, Clementi C, Peng J, Fullerton Jr PT, Prunskaite-Hyyrylainen R, Vainio SJ \& Matzuk MM 2017 BMP7 induces uterine receptivity and blastocyst attachment. Endocrinology 158 979-992. (https://doi. org/10.1210/en.2016-1629)

Paria BC, Ma W, Tan J, Raja S, Das SK, Dey SK \& Hogan BL 2001 Cellular and molecular responses to the uterus to embryo implantation can be elicited by locally applied growth factors. PNAS 98 1047-1052. (https:// doi.org/10.1073/pnas.98.3.1047)

Qi QR, Zhao XY, Zuo RJ, Wang TS, Gu XW, Liu JL \& Yang ZM 2015 Involvement of atypical transcription factor E2F8 in the polyploidization during mouse and human decidualization. Cell Cycle 14 1842-1858. (https://doi.org/10.1080/15384101.2015.1033593)

Saben J, Lindsey F, Zhong Y, Thakali K, Badger TM, Andres A, GomezAcevedo H \& Shankar K 2014 Maternal obesity is associated with a lipotoxic placental environment. Placenta 35 171-177. (https://doi. org/10.1016/j.placenta.2014.01.003)

Salleh N \& Giribabu N 2014 Leukemia inhibitory factor: roles in embryo implantation and in nonhormonal contraception. ScientificWorld/ournal 2014 201514. (https://doi.org/10.1155/2014/201514)

Santiquet N, Sasseville M, Laforest M, Guillemette C, Gilchrist RB \& Richard FJ 2014 Activation of 5' adenosine monophosphate-activated protein kinase blocks cumulus cell expansion through inhibition of protein synthesis during in vitro maturation in Swine. Biology of Reproduction 91 51. (https://doi.org/10.1095/biolreprod.113.116764)

Simon L, Spiewak KA, Ekman GC, Kim J, Lydon JP, Bagchi MK, Bagchi IC, DeMayo FJ \& Cooke PS 2009 Stromal progesterone receptors mediate induction of Indian hedgehog $(\mathrm{IHH})$ in uterine epithelium and its downstream targets in uterine stroma. Endocrinology 150 3871-3876. (https://doi.org/10.1210/en.2008-1691)

Singh M, Chaudhry P \& Asselin E 2011 Bridging endometrial receptivity and implantation: network of hormones, cytokines, and growth factors. Journal of Endocrinology 210 5-14. (https://doi.org/10.1530/JOE-10-0461)

Soyal SM, Mukherjee A, Lee KY, Li J, Li H, DeMayo FJ \& Lydon JP 2005 Cremediated recombination in cell lineages that express the progesterone receptor. Genesis 41 58-66. (https://doi.org/10.1002/gene.20098)

Stewart CL, Kaspar P, Brunet LJ, Bhatt H, Gadi I, Kontgen F \& Abbondazo SJ 1992 Blastocyst implantation depends on maternal expression of leukaemia inhibitory factor. Nature 359 76-79. (https:// doi.org/10.1038/359076a0)

Sun X, Park CB, Deng W, Potter SS \& Dey SK 2016 Uterine inactivation of muscle segment homeobox (Msx) genes alters epithelial cell junction proteins during embryo implantation. FASEB Journal 30 1425-1435. (https://doi.org/10.1096/fj.15-282798)

Tosca L, Froment P, Solnais P, Ferre P, Foufelle F \& Dupont J 2005 Adenosine 5 -monophosphate-activated protein kinase regulates progesterone secretion in rat granulosa cells. Endocrinology 146 4500-4513. (https:// doi.org/10.1210/en.2005-0301)

Tosca L, Solnais P, Ferre P, Foufelle F \& Dupont J 2006 Metformininduced stimulation of adenosine $5^{\prime}$ monophosphate-activated protein kinase (PRKA) impairs progesterone secretion in rat granulosa cells. Biology of Reproduction 75 342-351. (https://doi.org/10.1095/ biolreprod.106.050831)

Tosca L, Chabrolle C, Uzbekova S \& Dupont J 2007a Effects of metformin on bovine granulosa cells steroidogenesis: possible involvement of adenosine $5^{\prime}$ monophosphate-activated protein kinase (AMPK). Biology of Reproduction $\mathbf{7 6}$ 368-378. (https://doi.org/10.1095/ biolreprod.106.055749)

Tosca L, Uzbekova S, Chabrolle C \& Dupont J 2007b Possible role of 5'AMP-activated protein kinase in the metformin-mediated arrest of bovine oocytes at the germinal vesicle stage during in vitro maturation. Biology of Reproduction 77 452-465. (https://doi.org/10.1095/ biolreprod.107.060848)

Tosca L, Rame C, Chabrolle C, Tesseraud S \& Dupont J 2010 Metformin decreases IGF1-induced cell proliferation and protein synthesis through AMP-activated protein kinase in cultured bovine granulosa cells. Reproduction 139 409-418. (https://doi.org/10.1530/REP-09-0351)

Viollet B, Athea Y, Mounier R, Guigas B, Zarrinpashneh E, Horman S, Lantier L, Hebrard S, Devin-Leclerc J, Beauloye C et al. 2009 AMPK: lessons from transgenic and knockout animals. Frontiers in Bioscience 14 19-44. (https://doi.org/10.2741/3229)

Waker CA, Albers RE, Pye RL, Doliboa SR, Wyatt CN, Brown TL \& Mayes DA 2017 AMPK knockdown in placental labyrinthine progenitor cells results in restriction of critical energy resources and terminal differentiation failure. Stem Cells and Development 26 808-817. (https:// doi.org/10.1089/scd.2016.0252)

Wang H \& Dey SK 2006 Roadmap to embryo implantation: clues from mouse models. Nature Reviews: Genetics 7 185-199. (https://doi. org/10.1038/nrg1808)

Xu X, Leng JY, Gao F, Zhao ZA, Deng WB, Liang XH, Zhang YJ, Zhang ZR, Li M, Sha AG et al. 2014 Differential expression and anti-oxidant functio of glutathione peroxidase 3 in mouse uterus during decidualization. FEBS Letters 588 1580-1589. (https://doi.org/10.1016/j.febslet.2014.02.043)

Yang X, Xu P, Zhang F, Zhang L, Zheng Y, Hu M, Wang L, Han TL, Peng C, Wen L et al. 2018 AMPK hyper-activation alters fatty acids metabolism and impairs invasiveness of trophoblasts in preeclampsia. Cellular Physiology and Biochemistry 49 578-594. (https://doi.org/10.1159/000492995)

Yin X, Pavone ME, Lu Z, Wei J \& Kim JJ 2012 Increased activation of the PI3K/AKT pathway compromises decidualization of stromal cells from endometriosis. Journal of Clinical Endocrinology and Metabolism 97 E35-E43. (https://doi.org/10.1210/jc.2011-1527)

Yoo JY, Yang WS, Lee JH, Kim BG, Broaddus RR, Lim JM, Kim TH \& Jeong JW 2018 MIG-6 negatively regulates STAT3 phosphorylation in uterine epithelial cells. Oncogene 37 255-262. (https://doi.org/10.1038/ onc.2017.335) 
Yoshino O, Osuga Y, Hirota Y, Koga K, Hirata T, Yano T, Ayabe T, Tsutsumi O \& Taketani Y 2003 Endometrial stromal cells undergoing decidualization down-regulate their properties to produce proinflammatory cytokines in response to interleukin-1 beta via reduced p38 mitogen-activated protein kinase phosphorylation. Journal of Clinical Endocrinology and Metabolism 88 2236-2241. (https://doi.org/10.1210/jc.2002-021788)

Zhang L, Patterson AL, Teixeira JM \& Pru JK 2012 Endometrial stromal beta-catenin is required for steroid-dependent mesenchymal-epithelial cross talk and decidualization. Reproductive Biology and Endocrinology 10 75. (https://doi.org/10.1186/1477-7827-10-75)

Zhang S, Lin H, Kong S, Wang S, Wang H, Wang H \& Armant DR 2013 Physiological and molecular determinants of embryo implantation. Molecular Aspects of Medicine 34 939-980. (https://doi.org/10.1016/j. mam.2012.12.011)
Zhu MJ, Du M, Nijland MJ, Nathanielsz PW, Hess BW, Moss GE \& Ford SP 2009 Down-regulation of growth signaling pathways linked to a reduced cotyledonary vascularity in placentomes of over-nourished, obese pregnant ewes. Placenta 30 405-410. (https://doi.org/10.1016/j. placenta.2009.02.001)

Received 29 August 2019

First decision 16 October 2019

Revised manuscript received 17 February 2020

Accepted 19 march 2020 